\title{
Metastatic Cervical Carcinoma
}

National Cancer Institute

\section{Source}

National Cancer Institute. Metastatic Cervical Carcinoma. NCI Thesaurus. Code C153387.

A carcinoma of the cervix that has spread to another anatomic site. 